\title{
Picturing 700 years of history Charting political and social relationships from the Statuti Sassaresi, a XIV century manuscript statute-book
}

\author{
Nicolò Ceccarelli ${ }^{1}$, Alfredo Calosci ${ }^{1}$ and Marco Sironi ${ }^{1}$ \\ 1 Laboratorio AnimazioneDesign, DADU, Università di Sassari, Italy \\ nceccare@uniss.it, alfredoc@negot.net, marcosironi@elitradesign.it
}

\begin{abstract}
In 1316 the town-republic of Sassari issued its 'Statuti', a collection of regulations describing the city's legal and administrative matters. Although the contents of the document vividly present many traits of the city's XIV century's life, the original form in which it came to us - in Latin and vernacular Sardinian - make it very inaccessible to the general public. In the 700's anniversary of the Statuti the local Historic Archives started a vast dissemination project involving us on the grounds of our expertise in communication design.

Over the following year our research unit was engaged in the production of an experimental informative platform in which various artifacts - three animated short films, an illustrated booklet, and a website, among the others - explore ways to enhance the degree of accessibility of such an important historical account to the general public.
\end{abstract}

A key step along this process was the understanding that as different users have varying abilities in processing the available information, to provide actual access to it implies varying degrees of interpretation of the text per se, which clearly raises questions of historical accuracy.

This brought to the development of a model in which a series of artifacts based on various degrees of 'proximity' - and therefore of interpretation - to the original text, can represent different access points for the understanding of an otherwise very inaccessible text.

Keywords: Info-graphics, isotype, cultural heritage, pictogram design 


\section{Introduction}

In 1316 the town-republic of Sassari, in Sardinia (Italy), issued its 'Statuti', a collection of regulations describing the city's legal and administrative matters. In the emerging frame of north and central Italian "Communal" culture autonomy, the appearence of similar statute-books can be considered a tenet of the movement that lead to the end of the feudal world.

Although similar to many contemporary city's legislations, the Sassari statutes are in a way unique. They combine in fact a body of justice deriving both from the Roman and the Barbaric Laws with ancient local customary practices peculiar to the history of insular Sardinia (

The document, that came to us as a large volume in parchment in two versions, one in Latin, the other in ancient logodurese (a form of ancient vernacular Sardinian), vividly represents various traits of the city's XIV century's life (Mattone 1986). Among these, its political structure, the way justice was implemented, the administrative system, building regulations, health and safety issues, presenting a lively fresco of the social structure of a city in Italy's Communal times.

In the event of the 700's anniversary of its issuing, in 2016, the local Historic Archives started a project for disseminating this extraordinary document through a series of cultural events and presentations. One important step of this effort was the high resolution digitalization of the original document, followed by its on-line publication (http://archiviostorico.comune.sassari.it/statuti/).

\section{A dissemination effort}

Beautiful in their elegant handwritten text, the volumes are hardly accessible to the general public. A first practical reason is connected with the uniqueness of the document itself, which for obvious preservation purposes needs to be stored and handled with extreme care. Moreover, beyond the scarce legibility of the XIV Century hand-writing itself and the ancient parchment's not always optimal state of conservation, the document's contents themselves are far from being of easy interpretation. Both the Latin and ancient Sardinian versions are written in archaic form. The language is technical and very specific and, as it was then customary, specific textual formulas and abbreviations are widely used throughout the text. The passing of time also ought to be taken in consideration. Although many of the general issues the Statuti deal with are still present in today's life, society as a whole has gone through significant changes. Time has taken its toll on other grounds too: many landmarks of medieval Sassari's mentioned in the Statuti - buildings, churches, squares and streets - are today hard to spot out, even for the historian: other simply no longer exist or have changed in name and function.

Other subtler elements make the dissemination effort even more challenging. Despite containing an incredible amount of useful informations to the expert, the 
volumes don't present to our contemporary eyes an obvious and comprehensive picture of Sassari's life in the XVI century.

A medieval statute was neither a chronicle or a touristic guide: it was rather a collection of regulations - often assembled quite randomly - dealing with various aspects of the local political, social, legal and economic life. As for many other similar documents of the time, their entries would not necessarily encompass much of what can be perceived useful, relevant, even of general use, to our contemporary eyes. Many of these issues, apart from offering a lively testimony of the city life of their time, often focused on very specific and practical issues. Despite being possibly considered pressing and sensible to those who lived there at the time, may appear irrelevant today. It must also be kept in mind that at the time of the Statuti many mundane matters would have possibly been dealt with through customary - often orally transmitted - set of habits. Such daily practices would have then made unnecessary to transcribe something which - being widely accepted - did not need to be made explicit, and therefore transmitted to us.

Finally, it is not necessarily true that the degree of attention devoted to specific issues - building standards, the private exploitation of public space, public health measures, for instance - automatically indicates their relevance. Issues covered with less depth through the documents may well be not necessarily less important, but maybe only less 'problematic', hence not requiring constant efforts and/or specific ruling.

As this overview of the many questions associated with the dissemination of a document like the Sassari Statuti outlines, the praise-worthy digital publication of the document by the Historical Archive's website does offer an improvement of the available access opportunities, but clearly does not per se suffice in bringing this extraordinary heritage to full light. Dissemination implies information to be put in context, read 'in between the lines', and this clearly requires interpretation and guidance.

\section{Contact: a dissemination journey}

The contact between the Historical Archives of Sassari's Municipality and our research unit was generated by a common interest in exploring ways in which a system of 'visual explanations' (Tufte 1998) can improve the dissemination of a unique resource of local heritage and history.

As we started working at this task, a rather stimulating design trajectory was offered by the America And Britain series of three volumes published in the 1940's (and today available on-line). The volumes, presumably intended to help bringing the people of the two main war allied closer, uses an effective combination of text, photographs and original informative charts (designed for the scope by the Isotype Foundation) to present a thorough comparative view on the two country's social, economic and political features. 
A specific section of one of the volumes, Our Two Democracies At Work (Smellie 1944), which presents two comparative charts of the two nation's formal structures of political and administrative power, particularly caught our attention.
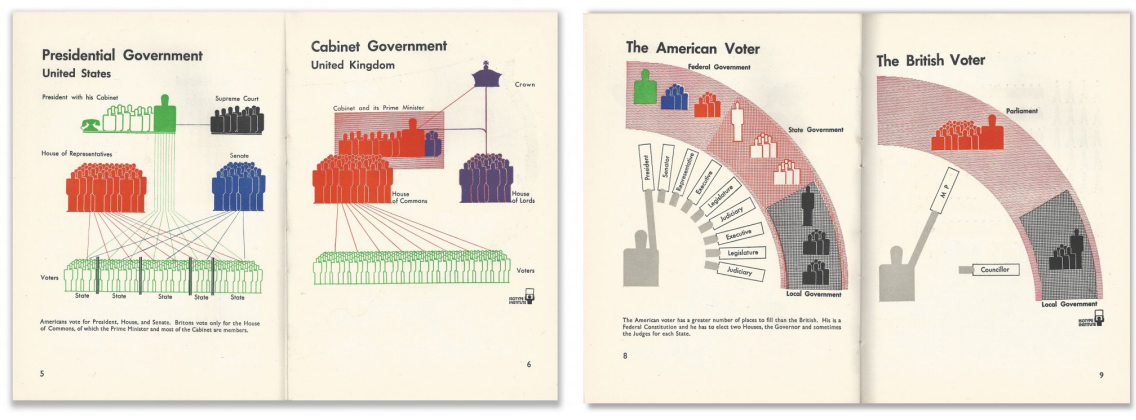

Fig. 1 Isotype comparative charts presenting parallel views of the political structures in the UK and the USA in the Our Two Democracies At Work volume.

Meant as offering a comparative perspective, the charts are structured as couples. The first one, Cabinet Government (UK)/Presidential Government (USA), based on a classic hierarchical diagram, depicts the two countries' political forms. A second pair: The British Voter/The American Voter presents the same structure and information from the subjective point of view of a citizen/voter in terms of its 'electoral potential'.

Apart from Isotype's usual spotless design and composition clarity, what we found particularly inspiring in the comparative arrangement of these charts was their effectiveness in naturally encompassing two totally different ways to 'tell the story'. While the first diagram is structured on an isometric-like point of observation - one giving to all components a same visual weight whilst hierarchically ordering them - the second chart illustrates the voter's position through an 'internal' conceptual arrangement, allowing to present the facts from a subjective specific point of view.

In reference to the history of graphic representation, we may highlight here the presence of a subtle visual arrangement. On the track of Erwin Panofsky's notorious reflections on Perspective as Symbolic Form, it is interesting to argue how in this specific metaphorical composition the image places the observer in the center of the scene. Although, geometrically speaking, the composition isn't strictly built as a perspective projection, it does present a conceptual 'perspective-like' point of view. Similarly to what happened with Renaissance painting, Panofsky's interpretation of the perspective projection as a symbolic device, the rhetorical solution of placing us in the centre of the scheme, offers a stimulating point of observation, contributing in bringing to light relationships that would otherwise remain distant and very abstract.

Through this elementary, and yet sophisticated, comparative conceptual device, the Isotype chart succeeds in connecting the abstractness of the political and administrative formal power structure - masterly depicted throughout a fine example of its 'in-house' isometric presentation style - with its 'reality' in terms of the network 
of interactions among the people that shape a community. It is a comparison within the comparison: almost a bi-directional magnifying glass, presenting in a concise, efficient and very convincing way, the two sides of a same coin.

\section{Early implementations}

On the track of this promising direction, our first step was developing a series of charts that, on the grounds of Isotype's classic methodology (Neurath, 1936, Kinross, 2009), present the social framework and distribution of power in 1300's Sassari.

This exploration was carried out within the first year design studio 'Comunicazione di Progetto' (Design Communication) at our school. Under our supervision, our students developed a series of basic charts and schemes visualizing information extracted from the analysis of the actual Statutes' text. The charts included various synoptic representations. Among these, graphs on the city's political structure at the time of the Statuti, as well as stylistic 'Isotype-like' representations (Frutiger 1989) of the key features of various figures mentioned in the text, developed on the grounds of their occupation and/or social status.
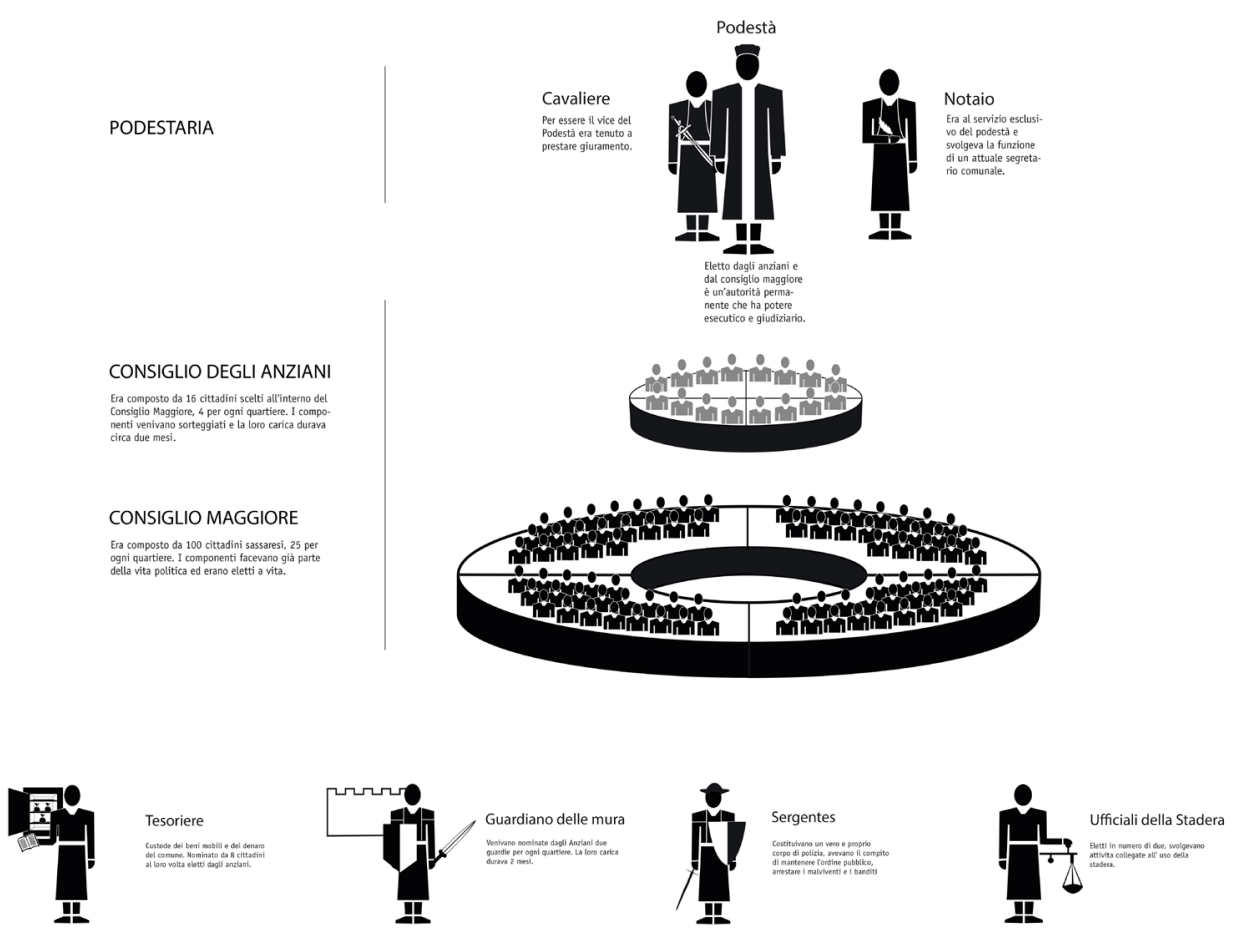

Fig. 2, 3 Two charts presenting a synoptic view of Sassari's formal power structure, as they are described in the text. Students: Giovanni Battista Asara, Chiara Muzzu, Ilaria Mundula, Alessia Rassu, Pasquale Messina. 


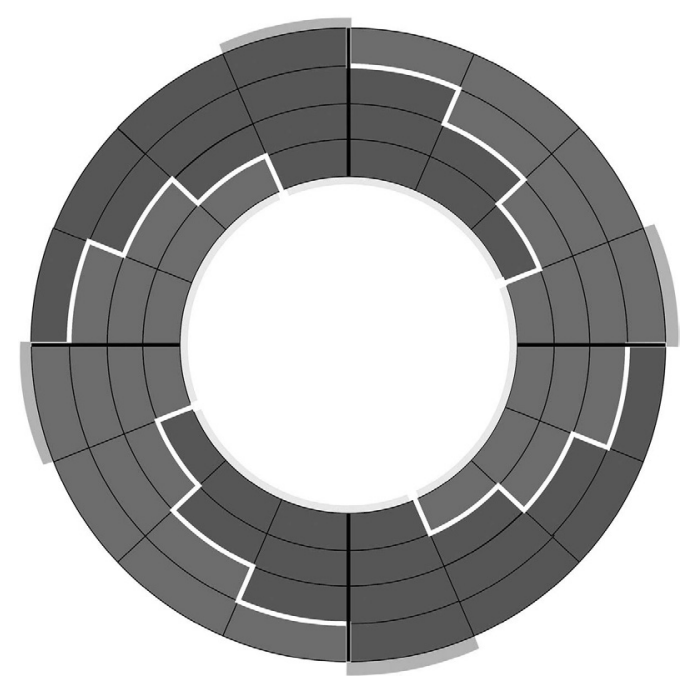

Fig. 4 Schematic chronologic representation of the ways in which Sassari Elder's council was elected. Students: Maria Laura Porqueddu, Fabrizio Palitta.

We readily acknowledged the potential of this approach for the visual development our project.

Although being based on the interpretation of a set of very elementary original information, the the representation of people (Abdullah and Hubner 2006) who actually lived in Sassari at the time of the Statuti, and the development of diagrams presenting the network of general responsibilities shared by a community and the related interactions, could allows us to bring to light, or at least to present, by analogy, actual relationships between real people living in 1300's Sassari.

Despite these early rather convincing results, we realized that developing a double comparative chart for Sassari in the XIV Century of the kind of the one in Our Two Democracies At Work would have been arduous. Further scrutiny of the available information highlighted in fact various difficulties and inconsistencies. Although technically possible, forcing the available facts into a comparative chart would correspond to twisting the historical facts, resulting in an inaccurate, or in an even incorrect, representation of the reality.

In order to achieve what we thought the America and Britain's charts provided best: a variety of different personalized perspectives, we needed to change strategy, redirecting our efforts to other ways to incorporate this element in our presentation. We hence started focusing on the elements that we thought made the Isotype institute's comparative pairs so effective: the combination between presenting information in a multi-scalar way and the adoption of an 'internal' point of view. The next step along this track was to find ways of connecting today's Sassari inhabitants with their 1300's peers. 


\section{Identities}

There can be little doubt about the fact that the over than 700 hundred years-old Sassari Statutes are, on many grounds, a powerful - although partially underrepresented - element of local identity. In this perspective, conveying to the actual inhabitants elements of such cultural and historical legacy becomes even more meaningful and relevant.

A first promising path in this direction has to do with what we may describe as 'geo-referencing'. Despite the many physical transformations that the city's structure went through over the past seven centuries, similarly to many other Italian towns of medium and small size, Sassari has retained a series of rather tangible spatial connections with its historical legacy. Landmarks mentioned in the Statuti can still be spotted within the city's actual form and built environment: in large still existing traits of the medieval walls and towers as well as in minor architectural elements such as corner-stones, columns, window-frames, plaques and inscriptions. Although not any more in place, historic sites such as the 'Carra Manna' and 'Carra Pizzinna' - specialized spaces that, according to the Statuti, where at medieval times used for weighting (for taxing purposes, in fact) goods entering the city - can still be traced through their toponyms. Similarly, the remains of the majestic gothic stone arcades in the 'Corso', in the heart of old Sassari, still provide a solid testimony of the existance of the Platha de Cothinas, the medieval city's high street (the only street to be paved at the time) along which all main public activities took place at the Statuti times.

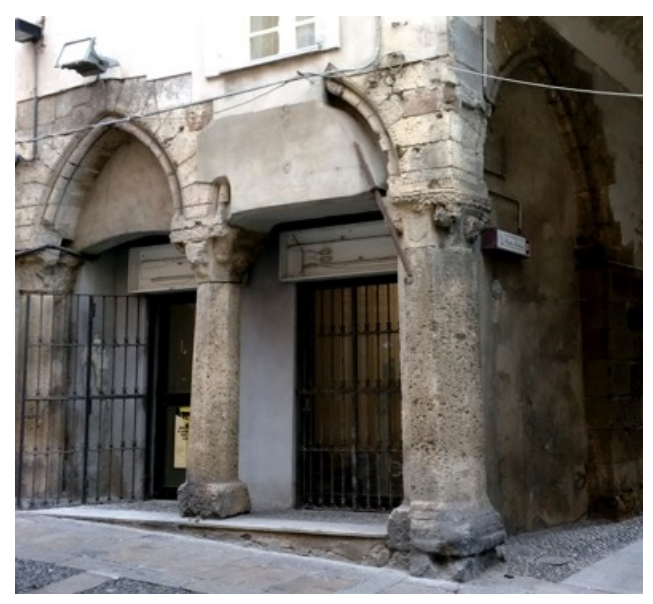

Fig. 5 Gothic portico remains in Sassari's old Platha de Cothinas

Although the full awareness of this legacy is lost in today's Sassari, once appropriately revisited and presented, these elements can play a powerful role in terms of reinforcing the local identity and a feeling of belonging. 
Another subtler, intangible and yet meaningful, level of connection lies in the parallel between the political status of the Sassari's Statuti and some current emerging trends in our society.

Over the last few years, developments in digital technologies and networking have triggered interest on ideas associated with the 'commons' movement and in its impact in social and cultural terms within increasingly aware communities. At the same time, a generalized loss of trust towards traditional forms of political representation has recently sparked in various countries (and this I certainly the case for Italy) a new attitude towards the idea of politics, which nowadays is more and more perceived as a shared responsibility involving certain forms of direct representation. It is not difficult to see connections between these trends and the ideals that drove to the Communal era.

It is easy to see that in such a perspective the Statuti text may today look unexpectedly modern and is bound to become increasingly interesting to broader public than that of the historians.

Having appraised the potential contribution of these components in the development of our project we went back to work looking for ways to spark an active interest within our public - the actual citizens of Sassari - beyond the acknowledgment of the existence of the Statuti documents per se.

\section{Establishing connections}

As finding ways to engage an audience is a key step for effectively communicating and transmitting information, we resolved to explore some classic approaches.

Being able to connect with the audience's direct experience is a valuable approach for reducing the apparent distance - and complexity - of a problem, making it easier to understand. Over time, classical rhetoric approaches have pursued a series of different strategies. Devices such as analogies, metaphors, allegories, are part of this toolbox, and well-known facts have become exempla, easy to grasp exemplary stories that can ease the adaptation of new information with patterns we already are familiar with (Zorzetti, 1980). This can be easily understood in cognitive terms, as it offers the advantage of presenting a framework for interpreting new information: a reference system for gauging the value of an otherwise unintelligible set of facts. Finally, the idea itself of associating, through some form of 'personalization', a new fact with existing knowledge and experience, contributes in making it more appealing.

As in Frances Yates' pivotal study on the art of Memory (Yates 1966), focused on classical rhetoric spatial-based techniques for structuring spatial mnemonic systems, and on more recent work by Lina Bolzoni (Bolzoni, 2002) on how images have been used to structure meaning in in late Medieval times, allegorical associations with 
buildings - palace, a tower - or other physical devices, a ladder to ascend to heaven, have been common through centuries to present complex information or, as Bolzoni highlights, to win over the common people.

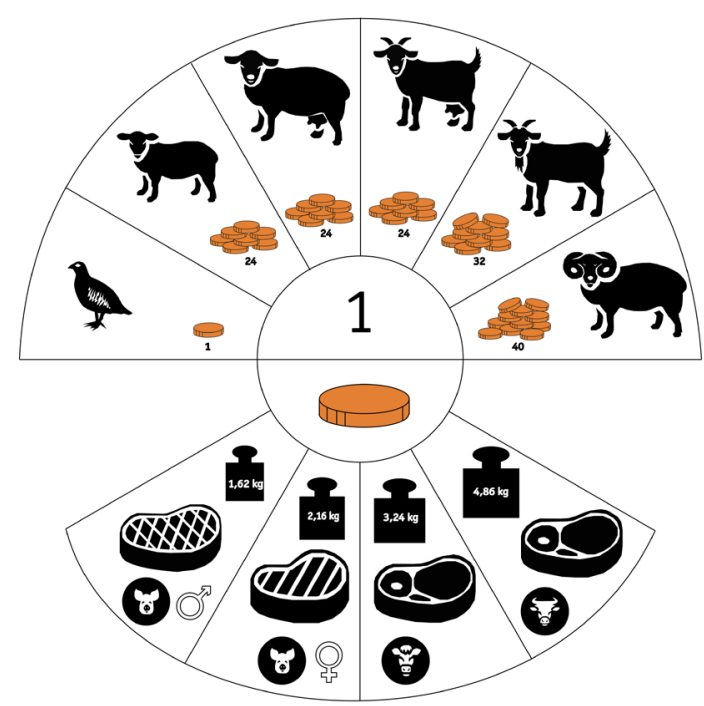

Potere d'acquisto: tre professioni

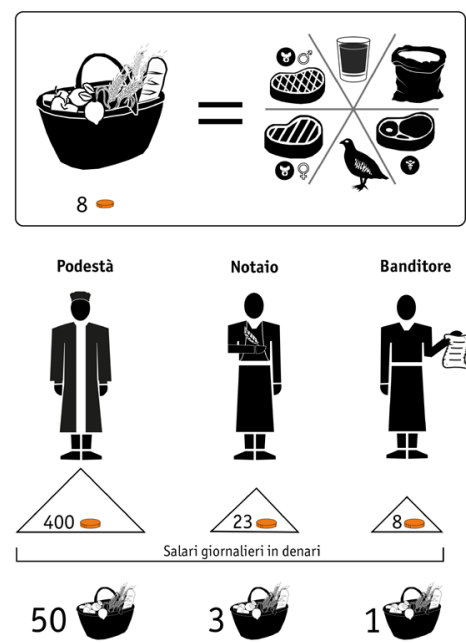

Fig.6 Visualization of meat prices (per unit and in weight) as they are listed in the Statuti, and food basket and comparative chart showing the spending power of different Sassari's 1300 city officers, based on available data on the average stipends. Students: Noemi Ena, Simona Piras, Daniela Tiana.

The idea of triggering an identification process between our audience and the people living at the Statuti time was instrumental to one of the most successful charts we developed with our students in the first phase of our research. The chart presents the prices of some foodstuffs, as specified in the Statuti, by visualizing them in as an ideal daily food basket of an average citizen of 1300's Sassari.

Combining information on the salaries of different people mentioned in the actual text, with an hypothetic basket of their families' respective daily allowances, has allowed us to depict the distribution of wealth across the city's social ladder at the time of the Statuti. This not only has made possible to present the existing differences in spending power between actual people - from the Mayor himself, yearly earning 600 Genoa Liras, to the humble "town crier" - but creates a powerful connection through time and space. Despite the many transformations occurred through time, and the obvious modifications in shopping habits, many Sassari inhabitants still visit regularly the city's central market to buy goods. Beyond being undisputedly exciting, the idea of being able to peep into a typical day's food basket of a fellow citizen who lived more than 700 years ago allows an ideal, and yet tangible, connection. 
Back to our project, one of main issues we were confronting with was how could we "tell our story" being able to spark interest beyond the circles of the learned historians and of the occasional curious. How could we achieve empathy among the actual 'Sassaresi' and their forefathers of more than seven centuries ago on the grounds of a few set of random and loosely related facts?

The direction we resolved to take was to focus on the balance between contextualizing information and actual varying informative demands of different potential users.

\section{Mise en scene}

Although the Statuti is an amazing source of information on a variety of different grounds, culling information from a document of this kind is not an easy task. Although often confusedly dispersed over the whole text, single facts and apparently fragmented units of information can, if re-organized within a broader picture, be turned into a significant reference base. But of course, such a re-organization of existing facts implies some form of information orchestration, which inevitably raises questions of historical accuracy.

Let's take as an example the market square, a fundamental public space in the life of any medieval town.

Although no direct description of Sassari's main market is to be found in the Statuti, the text presents text presents plenty of valid information to sketch what could have taken place there on a typical day.

We can be quite sure, for instance, that the city's centre attracted greengrocers (at the time mainly women, who carried to town the products of the many vegetable gardens located in the city's fertile surroundings). We know this indirectly, as a specific article in the Statuti expressly forbids them to card wool while selling their ware, supposedly in order to prevent any loose grains or fibers to end up in the goods.

From the Municipal procedures for taxing incoming goods, accurately listed in the text, we can instead learn about medieval customary units of weight and volume. The text also precisely describes how cheese, fish or leather, as well as many other goods, were to be sold. The cost for different meat cuts (used as a reference base in the food basket comparative chart we discussed earlier) is also prescribed in the Statuti, which among many other useful information also records the kind of fabrics or cloth one could expect to find on sale. We know the market's location (in Sassari today's 'corso', the city's Main Street) and that, in order to safeguard the decorum of its city core, the Statuti banished selling foodstuffs within a specific section of the corso itself.

As these examples make clear, the Statuti cover a multitude of on different areas of the social, economic, political life of the city life. And despite being often scattered within the entire text, many existing small snippets of information offer, once seen in their entirety, a rather comprehensive and vivid picture of Sassari's life at medieval times. From the point of view of anyone wishing to disseminate a 
document such as the Statuti, it isn't possible not to perceive these elements (places, people, things) as discrete informative building blocks, that once recombined with others through an accurate mise en scene process really can help addressing the varying needs and backgrounds of the document's public at large.

A grant from the Department for Education and Cultural Heritage of Sardinia's Regional Government in the area of research in audiovisual languages, offered our research team the opportunity to explore widely this idea over almost one year of very intensive work. The injection of fresh energy and resources provided to our project an even more stimulating perspective, allowing us to pursue a double, parallel, strategy.

Beyond achieving the more straightforward, and 'internal', objectives of our investigation - exploring the audiovisual medium's adaptability in treating different informative tasks - we realized in fact that our project could largely benefit by adopting a wider point of view. The original idea: developing a series of short films to test different informative patterns, would result significantly empowered if these were considered not per se, but as the components of a more comprehensive and integrated system. We then resolved on developing an informative environment that, by revolving around this audiovisual core, could provide multiple access points, offering an easier, less formal - and possibly more engaging - approach to the exploration of the Statuti.

\section{Framing contents.}

An important issue connected with the dissemination of any document has to do with the degree of interpretation it takes to make it meaningful to the general public. If we look at the Statuti as a 'raw' original material base this must necessarily be linked with the actual abilities of the potential recipients in receiving it as a source of information.

A scholar with extensive familiarity with ancient manuscripts and a good understanding of the political structure of Medieval communal cities (the kind of specialized 'visitor' one can find browsing through city historical archives throughout Italy), may have no problems in extracting information from the direct source. And in fact, a high-resolution digital version of the Statuti is available, on request, for scholarly purposes.

At the other side of the spectrum though, despite being possibly intrigued by the opportunity of browsing the newly-published on-line facsimile of the document, an average user will be mostly unable to obtain much useful information from it.

So, whereas we can expect the first type of user favor the digital facsimile's unfiltered information, the lack of background and skills will make that same source of information almost totally useless for the latter (as well as for ourselves, in fact). 
Whenever the goal is an effective dissemination of the document, some sort of compromise between these two extremes must then be sought after. Making information interesting and understandable to a public of non-experts implies adding context, which in turn leads to introducing varying degrees of interpretation to the original information. This obviously implies issues of historical accuracy: the idea of extracting bits of facts from an original context to re-combine them otherwise often horrifies historians. Any re-contextualization of historic facts is prone to be controversial, beyond any degree of rigor with which the selection of the single bits has been carried out - in our case in strict cooperation with the responsible of the local Historic Archive.

On the other side, what a waste for a document as extraordinary as the Sassari Statuti, to having survived over seven centuries of wars, famine, fires and riots, for the solitary pleasures a few knowledgeable experts.

The angle we resolved to take to approach this issue was to respond to the demands of different potential users by developing a series of specific informative artifacts, framed in a wider, comprehensive, informative system. The scheme presented in the below illustration, illustrates how the various artifacts we devised are intended to convey information to audiences with different backgrounds, combining narrative orchestration with proximity to the actual text (or, in other terms, their historic accuracy in strict terms).

The model is based on increasing degrees of interpretation, from left to right, of the original Statuti text.
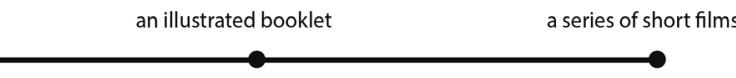

- degree of 'interpretation'

Fig. 7 The accuracy/interpretation scheme on which we have modeled our experimentations

Four distinct steps in this relationship where considered for the development of our research.

On the left side of the scheme is what already exists: the on-line digital facsimile of the Statuti books. Available for interactive browsing through the website of the Municipal Historical Archive (http://archiviostorico.comune.sassari.it/statuti/). Already on-line at the time of our involvement in the project, this is possibly the most unfiltered artifact available to the general public as it presents no, or very little, degree of interpretation.

On the opposite side of the scheme are the three audiovisual artifacts we developed in the course of our investigation. As we will discuss later on, by exploring 
different approaches to the original source in terms of language, tone and visual development, the short films themselves establish different degrees of proximity / interpretation with the text per se.

Between these two extremes, the reference model is completed by two intermediate steps.

Moving from left to right is an annotated version of the Statuti. This artifact, which we have only sketched as a prototype, can be thought as an extension - a hyperfacsimile, enriched by a system of cross-references - of the actual on-line digital version. Based on the actual text - here transcribed, and presented in the original (either in latin or ancient vulgar) versions as well as translated in Italian - this would present interactive explanations and contextualizations of the original text. Developed in the shape of a wiki-document, the relatively low degree of interpretation from the original source would be enhanced by a web of internal connections within the document contents. These may include a system of visual 'notes', in form of icons and other visual aids, to suggest cross-references and links to thematic areas of interest, linking to short textual integrative explanations and contextualizations, as well as to other and similar entries in the text.
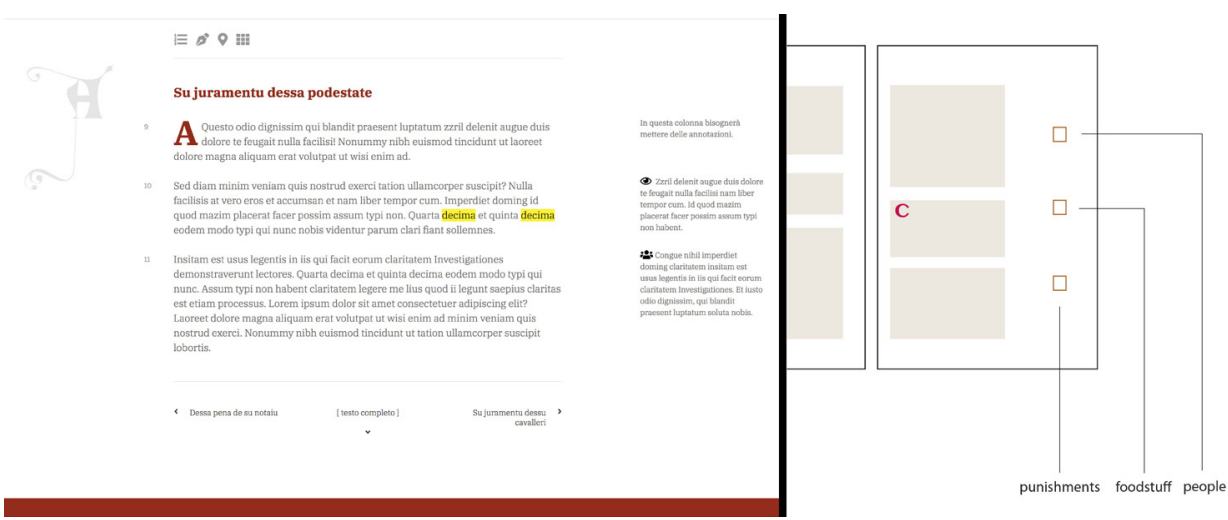

Fig. 8 Sketch for a prototype digital annotated version of the Statuti text. The original, transcribed, text is enriched by annotations, as in a hyper-document. Small iconic side labels may indicate that a specific piece of text can be used as a reference, possibly linking to similar ones, hence allowing the hyper-exploration of the whole text.

The following intermediate step in our reference model takes the form of an illustrated booklet, a light introductory guide to the Statuti, to be handed out to the visitors of the Municipal Archives, distributed in local schools and made available for free on-line download. 
The booklet - that we designed, illustrated, composed and printed - is a visual introduction to the Statuti and providing a general contextualization of the Communal era through focusing on some of its key social, political and economical traits. The booklet combines samples of the info-graphic charts developed by our students with a few illustrative full-page spreads. The spreads, which remind of 'living tableaux' reenact some specific moments of Sassari's life at the time of the Statuti. Each tableau presents plausible information - people, places, specific events and so on - which are combined through an intentional mise en scene process. Just as well as the selected elements, the already mentioned informative 'snippets', are extracted from the original text, these are presented with a direct reference, (a tag, in fact, coded in roman numerals) to the corresponding entry in the original text. Whereas possible, the contextualization has been reinforced spatially by referencing to architectural details still recognizable in today's city fabric.

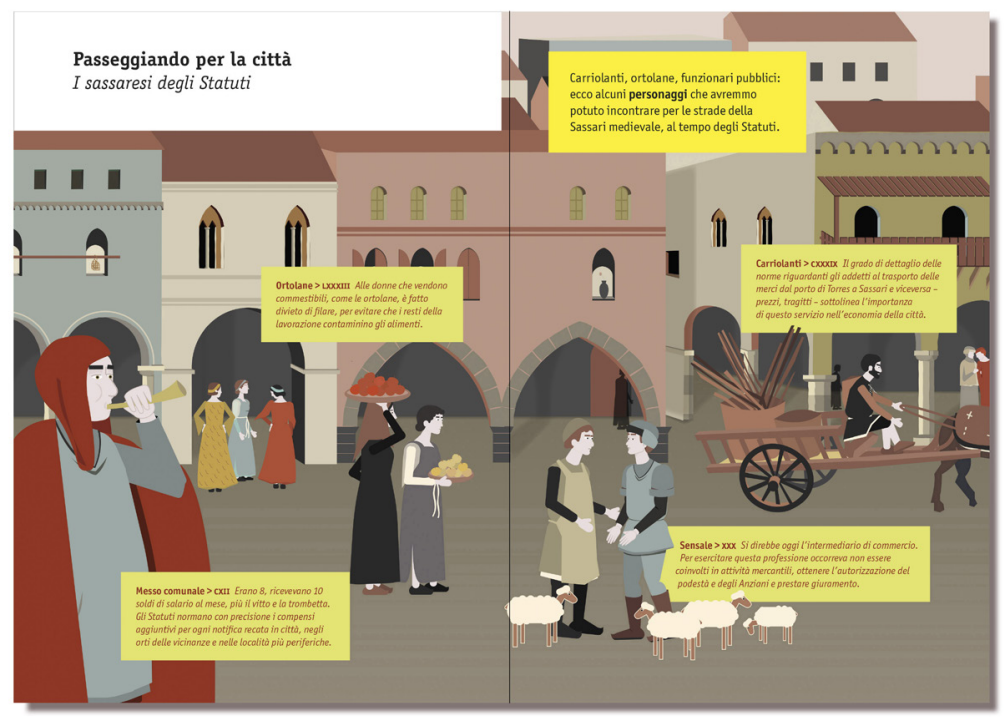

Fig. 9 Full-page spread from our illustrated introductory booklet. Thought as a sort of visual index, each spread combines various sets of informations about people, places and things, into a single comprehensive tableau.

Finally, as anticipated, the platform is completed by three animated short films - the subject of the funding we were granted by Sardinia's Regional Government for our 'Animating History' research project. The main focus of this part of the project is to explore the 'internal' capacity of the language of animation to address different informative tasks. Still, the intentional re-combination, in the films, of a series of units of raw information (extracted from the original Statuti text) into narrative 


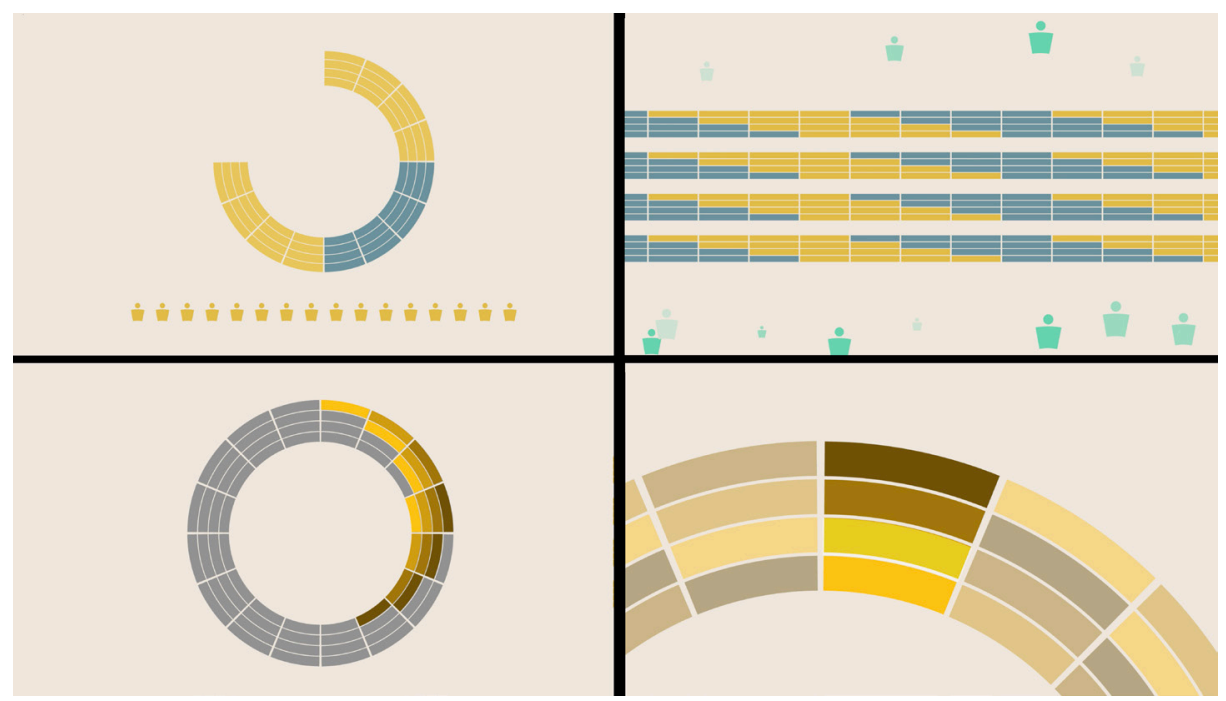

Fig. 10 Our first film, which presents the structure of Sassari's Elders Council, exploits a neutral-like general tone - based on an abstract info-graphics and a detached voiceover - to suggest the 'objective' interpretation of its workings and technicalities.

patterns, offers varying contextual degrees of interpretation, presenting interesting insights on the relationships between historical accuracy and accessibility.

The first of our short films The Elders Council presents the structure and the workings of one of the key political structures of Sassari's local government in the XIV century, focusing on its composition and on the duration of the counsellor's office. The piece has been developed as a distinctly abstract info-graphic presentation. The film's schematic visual treatment is reinforced by a neutral voiceover to convey the idea of an 'objective' interpretation of the presented facts.

Our second short The Sassari Statutes. An introduction, presents the specific circumstances of the Sassari Statuti within a general overview of the Communal age in Italy and Europe. The film is based on a series of descriptive scenes, arranged in the style of an illustration book. A detached voiceover comments what is being shown. The information is presented either directly or through the use of visual metaphors. Sound effects and camera moves are used to enhance the narration. The general atmosphere is deliberately that of the slightly pedantic pitch characteristic of many classic informative documentaries.

The goal of our third and final film $A$ day at the Market, is instead to engage the audience through an immersive dramatization of the Platha de Cotinas, Sassari's 1300 


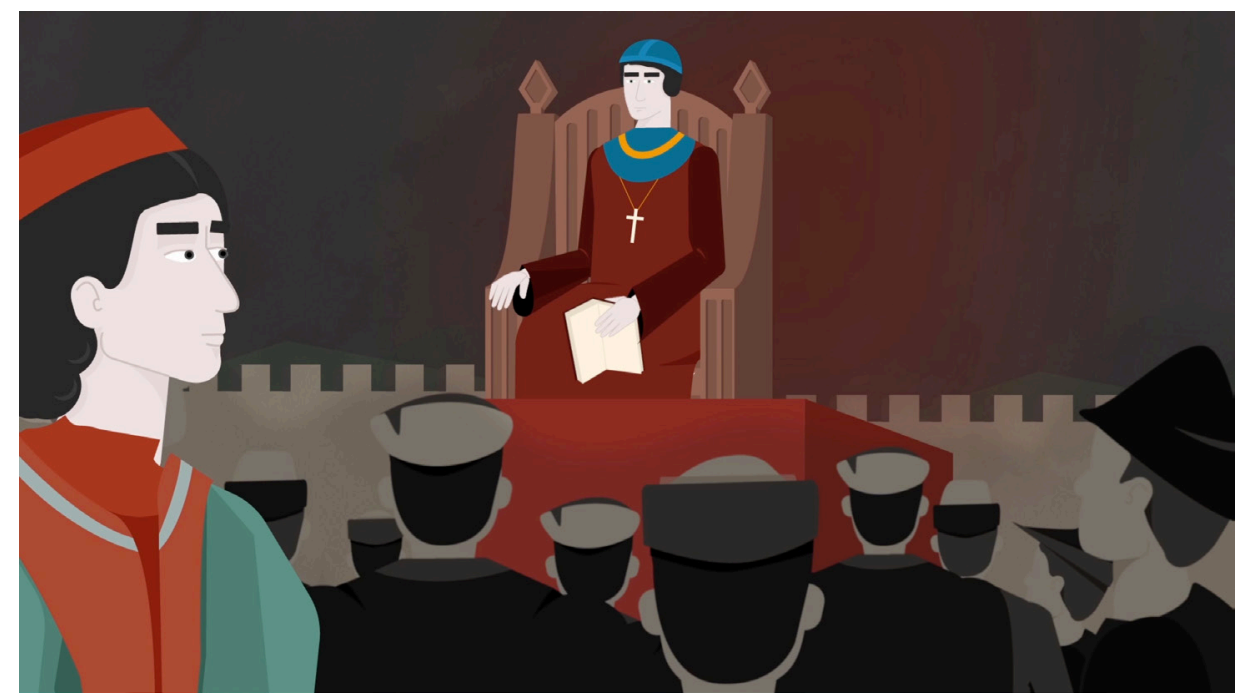

Fig. 11 One frame from our introductory animated film. The general tone of this specific piece is consciously modeled on the pedantic pitch characteristic of many informative documentaries.

central market. Several narrative artifices were put into place to recreate the atmosphere of a typical day in a medieval town. The film is intentionally composed as a unique long shot, aimed at suggesting the crossing of the market on a busy day.

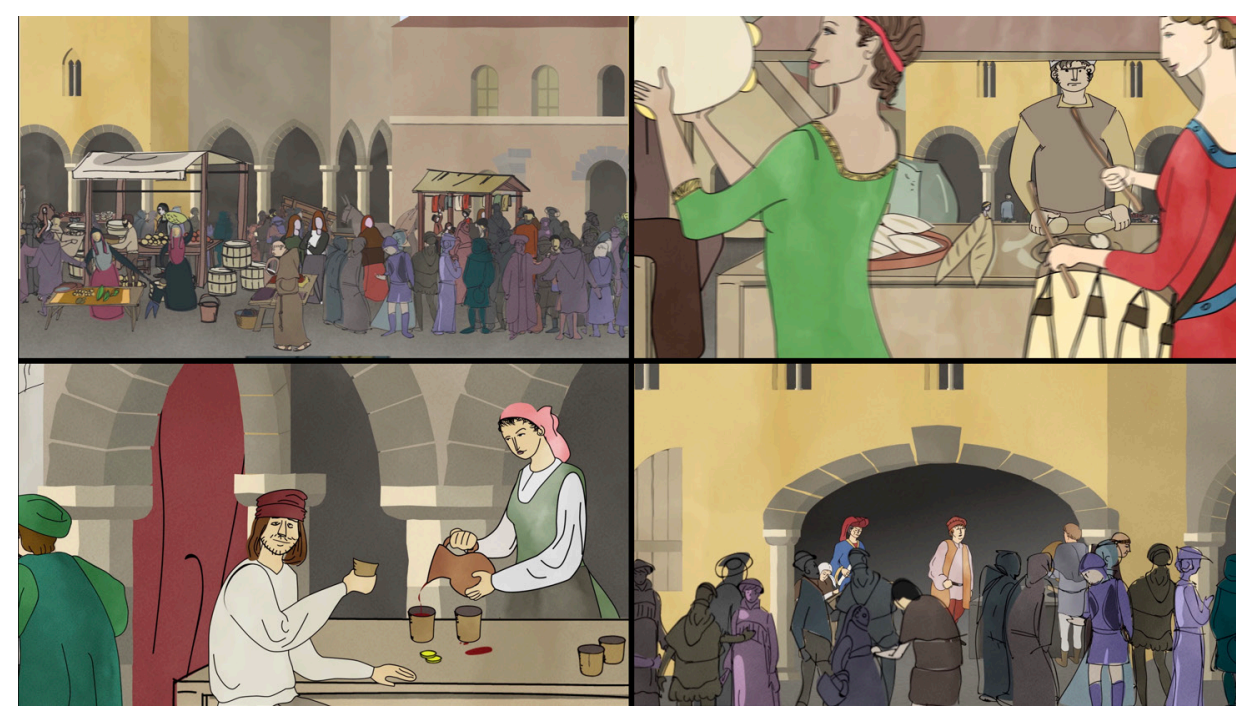

Fig. 12 The $A$ day at the Market film presents an immersive re-construction of a typical day in Medieval Sassari. 
The intentional absence of editing cuts is directed at offering to the contemporary public a spatial model of the Medieval city that can be ideally superimposed on the Sassari of today. Other narrative means - a voiceover narrator directly addressing the characters populating the market's stalls, which in some cases 'respond' by peeking into the camera - even a short 'Disney-like' music intermezzo depicting a group of dancing female musicians - are intended instead to remark the primarily fictional component of this specific artifact, and hence its distance in interpretativenarrative terms, from the previous two.

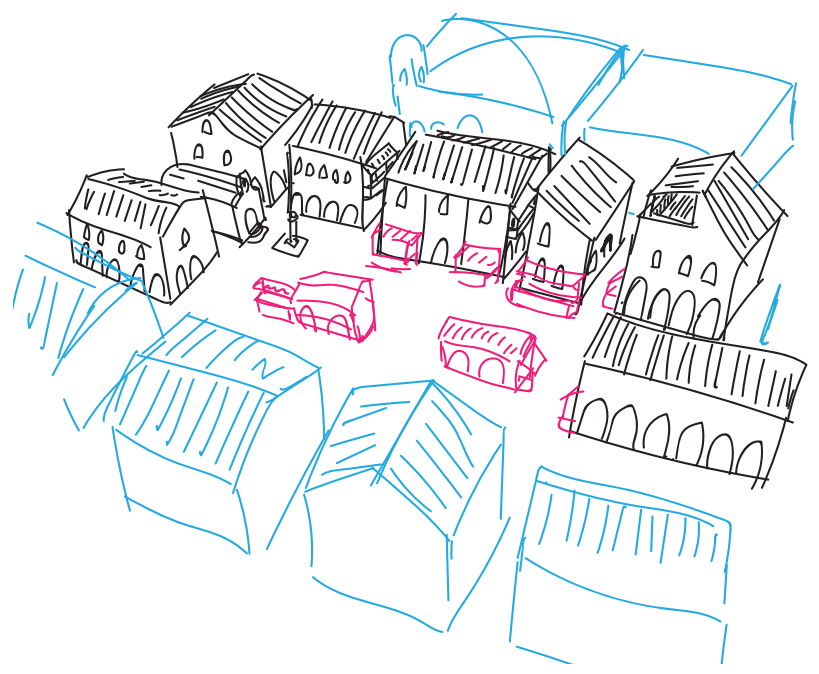

Fig. 13 Pre-production sketch of of Sassari's medieval city center as it was re-enacted in the $A$ day at the Market film. Based on a continuous long shot, the film cross-sections the entire market square incorporating reference to surviving fragments of the medieval structure presenting a mental map of the medieval structure that todays' inhabitants may superimpose over their perception of the actual city.

\section{Conclusions}

An applied research project has allowed us to confront with the dissemination of an exceptional historic document - the Sassari Statutes of 1316 - exploring the complex relationship existing between the two opposite objectives of preserving historical accuracy and favoring accessibility to a very dense piece of information.

One intensive year of work made possible to lay-out the grounds of a prototype informative framework - centered around three short animated films and a small introductory illustrated booklet - in which a series of different artifacts have been exploited to put this relationship to the test. 
At the heart of the experiment is a reference model in which the gradual parting from the nominal source's authenticity (as found in the original document) is complemented by an increase in the - intentional - contextualization and reinterpretation of the available raw information.

Along this line of work, and keeping as our main objective the making of the original source's contents accessible, we have experimented with ways to address this relationship by combining original 'facts' - units of information extracted from the original Statuti text - into narrative patterns that could help a public of non-specialists to relate to an otherwise very distant informative whole.

This approach had invariably affected the design of the prototype artifacts we developed for the project. Despite the very diverse ways - in terms of narrative structure, organizational pattern style and visual/animation language - in which the three films and small illustrative booklet we produced for the project have been developed, they all, we believe, result in a valuable insight on the possible trade-offs between a consistent representation of historical facts and their mise-en-scene aimed at improving their actual accessibility.

\section{References}

Abdullah, R., Hubner, R., Pictograms, Icons \& Signs. Thames and Hudson, London 2006

Frutiger, A., Sign and Symbols. Their Design and Meanings, Van Nostrand, New York 1989

Bolzoni, L., The Web of Images, Routledge, 2018 (Bolzoni, La rete delle immagini, Einaudi, Torino, 2002)

Madau Diaz, G.: Il codice degli statuti del libero Comune di Sassari, Editrice sarda Fossataro, Cagliari 1969

Neurath, O., International Picture Language, Kegan Paul, Trench Trubner \& co., London 1936

Panofsky, E., Perspective as Symbolic Form, Zone Books, New York, 1991

Rosenberg, D., Grafton, A., Cartographies of Time. A History of the Timeline, Princeton Architectural Press, New York, 2010

Smellie, K. B., Our Two Democracies At Work London, Toronto, G. G. Harrap \& company Ltd., 1944

Yates, F., The Art of Memory, Routledge, London, 1966

Zorzetti, N., Dimostrare e convincere: I'exemplum nel ragionamento induttivo e nella comunicazione. In: Mélanges del'Ecole française de Rome. Moyen-Age, Temps modernes, tome 92, n. 1, 1980. pp. 33-65 